\title{
PROCEEDINGS OF THE SOCIETY OF BRITISH NEUROLOGICAL SURGEONS: 64th MEETING
}

\author{
The 64th meeting of the Society was held on 23-25 November 1961 at the Derbyshire Royal \\ Infirmary, Derby. The President, Mr. D. W. C. Northfield, was in the Chair.
}

\author{
TREATMENT OF RUPTURED MIDDLE AND \\ ANTERIOR CEREBRAL ANEURYSMS DISTAL TO \\ THE CIRCLE OF WILLIS
}

R. SHEPHARD (Derby) discussed the treatment of middle cerebral aneurysms and also distal anterior cerebral aneurysms. He stressed the importance of the perforating arteries and described a method of operation which resulted in minimal disturbance of these vessels. He reviewed the position of carotid ligation, gauze wrapping, and acrylic investment in the present-day treatment of these cases. It was noted that exclusion of the aneurysm by clip or ligature was still the most common method used but whilst the mortality had been low disabilities in the survivors had been disappointingly high.

His present series comprised 220 unselected cases presenting with subarachnoid haemorrhage. Fifty-nine per cent of these proved to have aneurysms, 22 being middle cerebral. Bilateral carotid angiograms with three routine projections were done on all cases. In 12, intracerebral clots were shown, and in 13 cases arterial spasm. Five cases had two aneurysms, on the opposite artery in four and on the same vessel in one. Angiographic evidence indicated which had ruptured. Post-operative angiograms were done in 19 of the 20 survivors and exclusion of the aneurysm had been achieved in 18 of these.

Operation was carried out with controlled respiration and hypotension. The aneurysm was exposed by resection of the anterior $3 \mathrm{~cm}$. of the superior and middle temporal convolutions, leaving a portion of the superior to protect the Sylvian veins. The aneurysm was exposed from the distal end, the efferent middle cerebral vessels being exposed first; only the terminal millimetre or so of the main middle cerebral trunk needed to be exposed. The aneurysm was then clipped over gauze. Two distal (pericallosal) anterior cerebral aneurysms had been treated in a similar way by resection of a small portion of the frontal lobe. He stressed that exposure of the main middle cerebral trunk via the Sylvian fissure was inadvisable as manipulation of the vessel might provoke bleeding from the aneurysm and spasm of the vessel and its perforating branches.

There had been three deaths in 25 cases $(12 \%)$ and the follow-up period varied from less than six months (2) to over three years (4).

Of 22 survivors 18 had returned to their pre-operative work, three were employed on light work, and one was a recent post-operative case. One case showed a moderate expressive dysphasia due to the operation, the remainder showed considerable improvement on pre-operative neurological deficits. Epilepsy had occurred in seven cases. In one it was pre-operative and had not recurred; two had minor seizures in the early post-operative period; three had major attacks at long intervals; and the other patient had a single fit four months after operation.

He concluded that though the operative mortality of this operation did not differ materially from that of other procedures the disabilities amongst the survivors were few and the employment rate was higher than in published series where work status was mentioned.

\section{INDUCED HYPOTHERMIA IN NEUROLOGICAL SURGERY}

ALFRED UIHLEIN (Rochester, Minn.) described the experience obtained at the Mayo Clinic with the use of profound hypothermia in neurosurgery. He reviewed briefly the present state of knowledge of the effects of hypothermia on the central nervous system. He said that it had been shown that oxygen consumption by the brain was reduced to $50 \%$ by body cooling to $25^{\circ} \mathrm{C}$., to $25 \%$ at $22^{\circ}$, and to $3 \%$ at $5^{\circ} \mathrm{C}$. It had also been shown that reduced oxygen consumption by the brain in surface body cooling to between 25 to $28^{\circ} \mathrm{C}$. was related to reduced carotid blood flow which decreased more rapidly than oxygen consumption until a temperature of $24^{\circ} \mathrm{C}$. was reached when oxygen tension dropped rapidly. It could be shown that inhalation of $10 \% \mathrm{CO}_{2}$ with $90 \%$ oxygen produced a more parallel decrease in body and brain temperatures. He noted that systemic cooling below $28^{\circ} \mathrm{C}$. induced a risk of ventricular fibrillation and that surface cooling produced generalized vasoconstriction but systemic vascular cooling with extracorporeal circulation produced vasodilatation. Ventricular fibrillation might be avoided by the use of regional vascular cooling of the brain achieved by extracorporeal perfusion of the carotid artery. In this method rapid cooling of the brain to $10^{\circ} \mathrm{C}$. or less could be achieved while the general body temperature remained above $30^{\circ} \mathrm{C}$. This method might be complicated by cerebral embolization possibly due to carotid artery trauma or to the type of oxygenator used.

Eighteen patients with intracranial vascular lesions had been operated on under deep hypothermia as low as $11^{\circ} \mathrm{C}$. produced by whole body perfusion by the Drew technique and associated with total circulatory arrest. Four of these patients did not survive because of intracranial complications related to haemorrhage. The fifth died following a staphylococcal pneumonia. The remaining 13 patients recovered satisfactorily from the surgical procedure and convalescence was prolonged in only two instances. Post-operative psychometric studies did not reveal permanent brain damage following the operations. 
Post-operative electrocardiographic and cardiac output studies were normal. He stressed the need for meticulous haemostasis before circulation was re-established and after it had been completed. The possibilities of regional brain cooling and total body cooling with a closed chest technique were under investigation.

\section{TECHNIQUES AND PHYSIOLOGICAL ASPECTS OF PROFOUND HYPOTHERMIA}

DONALD ROSS (London) discussed the physiology of profound hypothermia and some of the techniques used. He said that mild hypothermia was used for head injuries, hyperpyrexia, and tumours. Its benefits had never been clearly defined and in his experience hypoxic brain damage was not uncommon. Conventional hypothermia had extensive use in cardiac surgery and allowed cardiac arrest of up to 10 minutes. Profound hypothermia he defined as below $25^{\circ} \mathrm{C}$. At these temperatures the heart was no longer competent to maintain circulation and some form of pump was necessary. It might appear that below $12^{\circ} \mathrm{C}$. tissue requirements for oxygen were very low or nil; venous blood might remain bright red even after 30 minutes' cardiac arrest. Though this meant that tissues were not using oxygen, it did not follow that they did not need it; it might not be available to them. Both cold and resulting low $\mathrm{CO}_{2}$ level reduced the availability of oxygen at cellular level. If the blood were warmed or $\mathrm{CO}_{2}$ added it immediately darkened so that oxygen was in fact needed by the tissues and used by them at low temperatures. It seemed advisable, therefore, to give $\mathrm{CO}_{2}$ enriched gas mixtures in the anaesthetic ( 3 to $5 \%$ ). The safe period of circulatory arrest could be estimated by measuring the oxygen tension $\left(\mathrm{pO}_{2}\right)$ in brain tissue. At normal temperatures $\mathrm{pO}_{2}$ fell to zero in three minutes. This period was prolonged as temperature fell and at $10^{\circ} \mathrm{C}$. $\mathrm{pO}_{2}$ fell to zero in 30 minutes. He concluded that the safe period for circulatory arrest was probably closer to 20 minutes than one hour.

He thought that profound hypothermia probably had its greatest use in neurosurgery in that it would allow short and, if necessary, repeated periods of circulatory arrest during which intracranial manipulations could be carried out in an avascular field. Two techniques were in use for this purpose and both involved an extra-corporeal circulation. The method of Drew was then described in which the patient's own lungs were used for oxygenation and a heat exchanger controlled temperature. He had used a heart-lung machine with disc type of oxygenator which was easier to use as only one pump was involved. He believed that a simpler technique was necessary if the method was to have wider application and this might be achieved by simple cannulation of the femoral artery and vein using external defibrillation if necessary.

\section{LOCAL CEREBRAL COOLING IN} NEUROSURGICAL OPERATIONS

K. KRISTIANSON (Oslo) described his method of local brain cooling in intracranial vascular leisons.
SOME NEUROSURGICAL ASPECTS OF HYPOTHERMIA AND EXTRACORPOREAL CIRCULATION

J. B. BRIERLEY (London) discussed the pathological findings in the brains of patients dying after open-heart surgery. Cases had been received from six surgical units and this report was concerned with the first 10 cases.

The first group consisted of two cases subjected to cardiac arrest under hypothermia alone. In the first case arrest was for four minutes at $31 \cdot 8^{\circ} \mathrm{C}$. Consciousness was never regained; there were signs of cerebral irritation, athetoid movements and left-sided fits. Death occurred on the tenth day. In the second case arrest was for $5 \mathrm{~min}$. 37 sec. at $28.8^{\circ} \mathrm{C}$. There was a period of ventricular fibrillation and cardiac massage for 60 minutes before normal heart beat was resumed. Death occurred after 48 hours without recovery of consciousness.

The brains showed softenings in the cerebral cortex, especially in the occipital region, and in the caudate and putamen. Microscopically in these regions there were areas of pallor with loss of nerve cells, surrounded by a narrow band of spongy tissue lacking the gliomesodermal reactions appropriate to their age. The central white matter showed some gliosis in one case and there was Purkinje cell loss in the cerebellum.

In the second group there were eight cases of hypothermia with perfusion but without circulatory arrest. Time of perfusion varied from 74 to 154 minutes and the range of hypothermia was 30.4 to $14.0^{\circ} \mathrm{C}$. Survival times were from 10 hours to 17 days.

Six of these cases showed 'geographical' lesions similar to the first two. These were sharply demarcated areas of abnormal cell staining or cell loss surrounded by a spongy area. There was a diffuse irregular neuronal loss in the cortex and irregular areas of partial demyelination in the subcortical white matter. These changes were most marked in the parietal and occipital lobes, being confined to the occipital region in two cases. There was no instance of vessel thrombosis and only one example of embolism from Teflon.

In two further cases one showed only a few perivascular haemorrhages and death was due to haemothorax, and renal and cardiac failure. The other showed the usual changes associated with cardiac arrest at normal temperature.

He concluded that these 'geographical lesions' were not associated with any age group, with a particular degree of hypothermia, or with perfusion. They occurred with circulatory arrest but also with hypotension. They were confined to the posterior parts of the brain and were largely in the grey matter. They did not have the character or distribution of the lesions of cerebral anoxia. He then discussed possible aetiological factors. With the patient supine, pooling of blood in dependent parts of the brain might play a part as might also delayed or uneven cooling in these areas. Vessel spasm might play a part and similar lesions had been seen in cases of cerebral aneurysm and subdural haematoma. 
EXPERIMENTAL AND CLINICAL OBSERVATION ON CERVICAL CAROTID BLOOD FLOW: A PRELIMINARY REPORT

W. EUGENE STERN (Los Angeles, Calif.) had applied the electromagnetic flow principle to the study of arterial flow through intact cervical carotid arteries in five animals and in two patients suffering from intracranial vascular malformations. He said that the values of carotid flow obtained by this technique were of the same order of magnitude as those reported by others with the use of differing methods of measurement.

A significant increase in unilateral carotid artery flow was noticed when the contralateral carotid artery was occluded both acutely and in a chronic preparation. The percentage increase was several times higher in animal (monkey and dog) than in man. Carotid flow was also strikingly enhanced during aortic occlusion but transiently fell below the pre-occlusion value on aortic release. Carotid flow also transiently overshot its pre-occlusion value when the carotid artery was itself released from occlusion. Occlusion of other major arterial channels such as the femoral artery caused a rise in carotid flow.

Unilateral carotid occlusion was associated with a rise in systemic blood pressure and such a rise was further augmented with the addition of bilateral carotid occlusion. Femoral artery occlusion, however, also raised systemic blood pressure as well as raising carotid artery flow. Carotid flow was related directly to systemic blood pressure and at least a significant part of this relationship appeared to depend upon the shunting of blood from one vascular bed to another during occlusion or release of a previously occluded major arterial channel. A redistribution occurred between vascular beds as the resistance was altered by such manoeuvres.

It was suggested that intracranially such shifts of blood occurred between the two halves of the circle of Willis when a carotid artery was occluded assuming the presence of adequate, patent vascular communications between the two sides. This shift of blood into an area of decreased resistance was associated with augmentation of flow through the remaining intact channels which potentially could supply such a deprived area. In the absence of adequate anatomical communication this augmentation was seen only in minor degree.

Observations from the utilization of the electromagnetic flow principle threw light upon intracranial vascular dynamics and the inter-relationships between intracranial and systemic arterial circulations but also posed questions and problems for future investigation.

\section{PRE-AXIAL ENTEROGENOUS CYSTS}

J. M. SMALL (Birmingham) described seven cases of enterogenous cysts lying in front of the neural axis: three gastric containing cysts pre-pontine in position; one foregut cyst in front of the cervical cord; two dorsal cord cysts; and one in front of the conus.

The theory of origin suggested was sequestration of entoderm during its contribution to the developing notochord. Similar tumours occurred in the posterior mediastinum and in the mesentery, and were associated with a high incidence of vertebral body abnormalities.

\section{GAS GANGRENE INFECTION OF THE BRAIN}

J. A. RUSSELL and J. C. TAYLOR (Derby) reported a case of gas gangrene infection of the brain in a man of 24 who had sustained a minor penetrating injury of the left temple with subsequent development of a brain abscess. A pure culture of Clostridium welchii was obtained from the pus. After treatment with repeated aspiration, penicillin, sulphadimine, and polyvalent anti-gas gangrene serum the patient recovered.

The literature was reviewed and 16 other fully documented cases had been found. From these and the present case the following points were made. All developed symptoms within seven days of wounding, often within 24 to 72 hours. In $29 \%$ symptoms appeared within this shorter time. Twelve cases were radiographed and of these eight showed gas bubbles. The mortality was $24 \%$.

\section{THERAPEUTIC USES OF RADIO-ISOTOPES}

JOHN HANKINSON (Newcastle-upon-Tyne) discussed his experience of the therapeutic uses of radio-isotopes. In one group pituitary destruction had been carried out for breast carcinoma, diabetes, acromegaly, or Cushing's syndrome. A stereotactic technique had been used with Leksell's instrument and a trans-sphenoidal route. Yttrium 90 , being predominantly a beta emitter, was preferable 0 to radon in these cases. Gold 198, which lay between the two in respect of beta emission, was being used in relatively low dosage to produce partial cell destruction in acromegaly. Pre- and post-operative hormone studies in recent cases had indicated satisfactory pituitary destruction. Partial visual loss had occurred in 12 cases and transient ptosis in two cases. Twelve cases developed polydipsia and five a transient cerebrospinal fluid leak.

He then discussed the use of isotopes in making cerebral lesions for involuntary movements. The lesions resulting from small rods of yttrium 90 were quite predictable and could be related to dosage by histological calibration. He had been able to demonstrate this in lesions made in animals. He did not think that change of position of the source in the brain was important in view of the short half-life of this isotope. It might also prove desirable in elderly patients to produce a lesion slowly over a period of days.

He then discussed the treatment of cerebral tumours by this method. Small, surgically inaccessible tumours strategically placed were best suited to this form of treatment. In practice this meant those tumours well outlined radiologically in relation to the third ventricle, either 'pinealomas' posteriorly or craniopharyngiomas anteriorly. Small rods $(3 \mathrm{~mm}$. $\times 0.8 \mathrm{~mm}$.) of gold 198 of dose 1 to $2 \mathrm{mc}$ introduced by stereotactic methods had proved satisfactory. The dosage and distribution were planned to provide 7,000 to 10,000 rads. Tumours involving the posterior part of the third ventricle had yielded the best results with loss of physical signs and reduction of intracranial pressure. Five of these patients were alive and well five, three, two, and one year after treatment. 
He noted that the clinical features suggested that there was significant swelling of the tumour for 72 hours following irradiation and this fact should exclude pituitary tumours showing any degree of chiasmal involvement. Attempts to treat larger cerebral tumours, such as hemisphere gliomas, had been unsuccessful and it seemed unlikely that adequate irradiation of a tumour bed after subtotal excision could be achieved by this method.

\section{MYODIL VENTRICULOGRAPHY IN THE DIAGNOSIS OF PINEAL REGION TUMOURS}

BRYAN JENNETT, RICHARD JOHNSON, and REGINALD REID (Manchester) discussed the use of Myodil in the diagnosis of tumours in the pineal region in a series of 29 patients. It was noted that the diagnosis of these tumours rested largely on radiological appearances; the clinical features were neither constant nor pathognononic. Air ventriculography was not always satisfactory in demonstrating this region clearly and there were considerable dangers in this procedure in patients with obstructive hydrocephalus and raised intracranial pressure.

Myodil not only gave consistent visualization of the third ventricle but might show fissures and ulcers in the wall which air would not fill. There was no need for urgent surgery after this procedure which might be carried out over two days.

In their series they had hoped to distinguish between excisable cysts, malignant growths and tumours, such as the ependymoma, which might benefit from irradiation, and to recognize distortion of this part of the ventricular system from upward growth of vermis tumours.

Over half the patients had an aqueduct block, but when the examination was persisted with for several hours some dye frequently began to trickle past what had seemed to be a total obstruction. In this way useful pictures of the aqueduct were obtained; it was often displaced forward more than a centimetre from its usual position. The filling defects in the third ventricle were sometimes smooth crescents, single or multiple, and the only four patients to survive more than three years without recurrence were in this group. When the defect was irregular the prognosis was bad; the majority died within a year. In four of these patients a ragged diverticulum of the posterior end of the third ventricle was recognized, and in two some Myodil escaped into the subarachnoid cisterns. This appearance they took to indicate a necrotic, malignant tumour.

In the 15 tumours verified glioma was the commonest; only two pinealomas were found. The outlook for the group was bad, 20 already being dead, 17 of them within a year of diagnosis and treatment.

URINARY INCONTINENCE AND FRONTAL LESIONS

J. ANDREW (Romford) discussed the question of urinary incontinence after frontal lobe lesions. Cases of leucotomy, penetrating, brain injury, frontal tumours, subarachnoid haemorrhage, and operated aneurysms on the anterior part of the circle of Willis had been investigated by cystometry. Patients undergoing leucotomy often showed reduced bladder capacity, lack of feeling of distension, and uninhibited contraction.

These changes might occur even when there was no incontinence after operation. The cystometric patterns usually approximated to three types found from infancy to the early years of life; this suggested that bladder function was regulated at lower levels within the central nervous system which had been superseded during the earlier years of life with development of frontal lobe function. Another type of pattern was found-a low tension bladder with increased volume. This was associated with loss of both feeling of distension and detrusor activity and was similar to the cystometrogram in acute spinal cord lesions. There was often unsuspected retention of urine with overflow. This should always be looked for when incontinence complicated acute frontal lesions. The role of bladder infection was important, as it could precipitate incontinence in patients who might otherwise be dry.

The investigation suggested that bladder sensation was represented fairly diffusely within the frontal lobes, but particularly in their medial aspects. It was remarkable how often sensation was impaired and incontinence occurred, to the distress of patients who had a well preserved intellect. It was concluded that incontinence in patients with frontal lesions was not necessarily due to dementia and apathy, and that it might be occasioned by focal damage to the frontal lobes in areas specifically concerned with bladder sensation and motor control.

\section{HYDROMYELIA}

E. J. NEWTON (Stoke-on-Trent) described three cases of cervico-dorsal hydromyelia. They presented clinically with characteristic symptoms and signs of central cord and lower brain-stem involvement. Lumbar puncture revealed a partial block in one case and complete block in one with cerebrospinal fluid proteins of 110 and $50 \mathrm{mg}$./ $100 \mathrm{ml}$. respectively. Radiological evidence of enlargement of the cervical canal was seen in two cases and myelography showed a fusiform enlargement of the cervical and upper dorsal cord in all three. In all three patients mid-cervical laminectomy revealed a large longitudinal cyst in the cord from which a clear, colourless fluid was aspirated. The protein content of this fluid varied between 19 and $36 \mathrm{mg}$. $/ 100 \mathrm{ml}$. In each case an opening was made into the dorsal aspect of the cord to drain the cyst into the subarachnoid space. The operative exposure was carried up into the posterior fossa in two cases. In one case an enormously dilated fourth ventricle with atresia of its outlet foramina was found and a large opening was made in its roof. In this case the hydromyelic cyst extended into the medulla on the left side and could be seen through the floor of the fourth ventricle. In another case a firm extradural band at C.2 level was divided, and the cord cyst was found to end here. All three cases improved after operation.

The composition of the liquid in these cysts indicated that it was probably cerebrospinal fluid which had come from the fourth ventricle via the central canal. It was suggested that distension of the central canal (primary hydromyelia) might result in rupture of its ependymal 
lining and the formation of a diverticulum which might then extend up and down the cord between fibre bundles (secondary hydromyelia), pushing the central canal to one side. This kind of eccentric cyst could extend into the brain stem and would account for asymmetrical cord and bulbar signs, as well as the finding in post-mortem studies of a large cyst separate from the central canal.

SOME USES OF METHYL METHACRYLATE IN SURGICAL NEUROLOGY

PHILlIP HARRIS (Edinburgh) discussed the clinical, physical, and biological features of methyl methacrylate in relation to its use as an implant in the body. Studies on the strength of the material were described, and methods of sterilization were criticized.

He mentioned various uses for methyl methacrylate in surgical neurology, including the manufacture of special surface scalp-skull markers that he is using to speed up the initial part of the stereotaxic procedure, employing the Guiot type of apparatus. Cranioplasty, the investment of certain intracranial aneurysms, and fixation of parts of the spinal column could also be achieved by means of methyl methacrylate.

\section{THE FEBRUARY 1962 ISSUE}

\section{THE FEBRUARY 1962 ISSUE CONTAINS THE FOLLOWING PAPERS:-}

Post-tetanic Potentiation of Myotatic Reflexes in Man KARL-ERIK HAGBARTH

Peripheral Nerve Conduction in Diabetic Neuropathy R. W. GILLIATT and R. G. WILLISON

Some Circulatory Responses to Valsalva's Manoeuvre in Patients with Polyneuritis and Spinal Cord Disease W. E. WATSON

Cerebral Complications of Hypotensive Anaesthesia in a Healthy Adult J. B. BRIERLEY and J. E. COOPER

A Myasthenic Syndrome Associated with Bronchial Carcinoma. R. P. WISE and VIOLET MACDERMOT

Tentorial Meningiomas HOWARD S. BARROWS and DONALD H. HARTER

The Migrainous Symptoms of Cerebral Angiomata F. LEES
Non-infectious Granulomatous Angiitis of the Nervous System Associated with Hodgkin's Disease NEILL B. REWCASTLE and MARY I. TOM

Birth Order in Epileptic Children T. COLVER and D. F. KERRIDGE

Familial Cerebro-macular Degeneration and Ataxia J. B. FOSTER and T. T. S. INGRAM

Phantom Experiences Following Amputation in Childhood MARIANNE L. SIMMEL

Effect of Intrathecal Purified Protein Derivative of Tuberculin in Multiple Sclerosis JACK COLOVER, MICHAEL KREMER, R. E. LOVELACE, and J. R. SILVER

Stereotactic Surgery: A Note on Instrumentation VERNON H. MARK, WILliAM H. SWEET, and PAUL M. MCPHERSON

Book Reviews

Copies are still available and may be obtained from the PUBLISHING MANAGER, BRITISH MEDICAL ASSOCIATION, TAVISTOCK SQUARE, W.C.1, price 17s. 6D. 